\title{
MOBILITY OF POTENTIALLY TOXIC ELEMENTS FROM THE ABANDONED URANIUM MINE'S SPOIL BANK
}

\begin{abstract}
This study is part of the ongoing environmental monitoring program of the abandoned Mecsek uranium mine during the remediation period. During this program on the recultivated No.1 spoil bank, the radioactivity and the potentially toxic element (PTE) contents in the covering soil had shown some anomalies which refers to possible migration alongside the slope. Therefore, in a previous study, soil and plant samples were collected from top to bottom position of the slope and the total element content was determined by multi-elemental inductively coupled plasma-optical emission spectrometry. The results have indicated that there was a high possibility for PTEs to be mobile and available for uptake by plants. To confirm this indication in the present study for the soil samples the BCR sequential extraction procedure was applied to characterise the environmental mobility of PTEs, and it was compared with soil $\mathrm{pH}$ and cation exchange capacity (CEC). The results indicated that the ratio of $\mathrm{Cd}$, $\mathrm{Co}, \mathrm{Mn}, \mathrm{Pb}$, and $\mathrm{U}$ in the non-residual fractions ranged between 36.8 to $100 \%$ and increased from top to bottom direction. The comparison showed that the samples with the lowest $\mathrm{pH}$ and CEC had the most mobility of the PTEs. The distribution of $\mathrm{U}, \mathrm{Cd}, \mathrm{Mn}, \mathrm{Co}$, and $\mathrm{Pb}$ in fractions indicated that some parts of the spoil deposit require additional steps to hinder the migration through the covering soil layer, and the BCR sequential extraction procedure has proven to be useful in providing information for the planning and management of remediation operations.
\end{abstract}

Keywords: BCR sequential extraction, potentially toxic element, soil, mobility, uranium mining

\section{Introduction}

Uranium mining legacy sites are products of anthropogenic activities of which in many countries are of particular concern because of the inevitable incidence of waste deposits with elevated concentrations of radionuclides and their possible environmental health effects [1]. Mine spoil deposits which are rich in potentially toxic elements (PTEs) can be affected by water and/or wind erosion, spreading the contamination to surrounding areas [2]. Similarly, Kabata-Pendias [3] states that the mobility processes and the availability of elements are regulated by many factors including geochemical, climatic, and biological origin. Additionally, Valencia-Avellan et al. [4] pointed out that the increasing frequency and magnitude of rainfall series events are the key factors that may affect the mining areas by re-mobilising and transferring metal-rich sediments and increasing metal-rich runoff, impacting the quality of river water. Furthermore, Smiciklas and Sljivic-Ivanovic [5] assert that the rainfall and the soil's ability to immobilise elements are essential factors for

\footnotetext{
${ }^{1}$ Department of Environmental Analysis and Technologies, Institute of Environmental Sciences, Hungarian University of Agriculture and Life Sciences, Páter Károly u. 1, 2100 Gödöllő, Hungary

${ }^{2}$ Bányavagyon-hasznosító Nonprofit Közhasznú Kft (Mining Property Utilization Ltd.),

Tarsay Vilmos u. 3. 1. em., 1126 Budapest, Hungary

*Corresponding author: Horvath.Mark.Kalman@uni-mate.hu
} 
regulating activity concentrations available to biota. In addition, the $\mathrm{pH}$ and the cation exchange capacity (CEC) are part of significant factors that have an influence on mobility PTEs in the soil [6-10]. To evaluate the environmental effects of polluted soils, it is important to assess the bioavailability and speciation of PTEs [11].

In environmental and agricultural chemistry, various extraction methods are available simulating the various environmental conditions for the assessment of the overall PTE stock content and bioavailability [12]. Single-step extraction and sequential extractions are used, however, it is difficult to compare the data obtained from various sequential extraction schemes, due to the lack of uniformity in these procedures since the results rely heavily on the extraction method used [13, 14]. Therefore in order to strengthen this situation, the Standards, Measurements, and Testing Program (SM\&T), formerly known as the Reference Bureau of the European Community (BCR), initiated a joint project in 1992 aimed at harmonising and standardising the various procedures used in soil and sediment to fractionate metals [13-15]. A three-step sequential extraction technique based on the extraction of acetic acid (step 1), hydroxylamine hydrochloride reduction (step 2), hydrogen peroxide/oxidation acetate (step 3) has therefore been developed and later modified [16]. Rauret et al. [13] acknowledge that there are issues with the three-step extraction system, such as low reproducibility. Although the implementation of sequential extraction schemes may include problems such as non-selectivity, re-adsorption, etc., these methodologies are important for metal fractionation in order to predict metal mobility and bioavailability $[17,18]$. Heltai et al. [19] reiterate that the use of BCR-sequential extraction continues to be the traditional technique for evaluating environmental risks of PTE pollution considering these methodological problems, thus offering the potential for quantitative analysis of environmental mobility. Sequential extractions, as contamination indicators offer a fair compromise between knowledge on the distribution of material between solid fractions or components and the potential risks involved with their mobility or distribution [20].

The analytical results obtained from sequential extractions can be used to calculate the mobility factor, $M F$ [21]. $M F$ has been used in many studies to evaluate the mobility of PTEs in soil [8, 12, 14, 22, 23]. High $M F$ values indicate a relatively high potential for mobility and biological availability of PTEs in soils, while low $M F$ values reflect the high stability of PTEs in soil [23].

The present study is part of the ongoing environmental monitoring program to monitor the endangered and contaminated compartments in the period of mine closure, remediation, and post-closure operation in the Mecsek uranium mine [24]. As part of the remediation process, every three to five years, samples are taken from all the covering soils of spoil deposits in the Mecsek uranium mine to monitor the content and the migration of radionuclides and PTEs. In this monitoring program, the total strong-oxidative acid digestible (pseudo-total) concentrations of elements are also measured in the soil, water (groundwater, seepage water, mine, and treated mine water), and covering plants [24]. The results indicated that out of all spoil deposits monitored, deposit No. 1 soil cover layer was found to have been damaged due to the erosion wounding that had occurred during the remediation process. Additionally, the International Atomic Energy Agency (IAEA) [25] reported on the results for the data collected at the Mecsek mine between 1996 and 2000 during one of the key tasks of this monitoring program. In this report, it was stated that a significant amount of different chemicals, seeped into the groundwater from the tailing ponds causing significant pollution of shallow and partly deeper groundwater aquifers. Consequently, the contaminated groundwater is drained and treated before being released. 
Based on these findings of the monitoring program, spoil deposit No. 1 was deemed to require further investigation on the mobility of radionuclides and PTEs. This study is the continuation of the research studies conducted by Khumalo et al. [26, 27] in which the radioactivity in covering soil and plants have been analysed and the pseudo total concentrations of PTEs in soil and plants were determined on spoil deposit No. 1. From the top, slope, and bottom positions of the spoil deposit, core soil samples, and plant samples were taken from the covering soil to study the PTE migration retarding capacity of the covering soil. It was established that there is a possibility of PTE migration by water leaching from the top to the bottom of deposit No. 1. This was also indicated that by soil/plant transfer factors calculated from these measurements [27]. However, there have not been studies conducted in this study area on the mobility of these elements using the BCR extraction technique. The prediction of soil metal phyto-availability using chemical extractions is a conventional approach routinely used in environmental and agricultural soil testing [28]. A typical sequential chemical extraction such as the BCR procedure starts with a less aggressive solvent, followed by more and more aggressive solvents in order to sequentially solubilise various operationally defined metal fractions [29]. The soluble plus exchangeable plus carbonate bound fraction contains the most phyto-available forms of metals, while those in the latter stages of the extraction scheme are less available to plant. These methods enable measurement of wider aspects or phases (e.g. bioavailability) and, in the majority of cases, it is adequate for environmental policy purposes [13]. Hence, sequential extraction procedures have remained very useful for understanding the chemistry of PTEs in soils despite numerous criticisms [30]. Therefore, the main goal of this study is to determine the environmentally available PTEs by using the BCR sequential extraction procedure to evaluate the efficacy of the soil covering layer of the spoil deposit No. 1 of the abandoned and recultivated uranium mine. The mobility was compared with the soil $\mathrm{pH}$ and the CEC of the covering soil.

\section{Materials and method}

\section{Study area and sampling}

In 1953 Mecsek uranium mine started to produce uranium from a low-grade underground sandstone ore $(0.07-0.12 \%$ U) [31]. Furthermore, Juhasz and Erdi-Krausz [31] state that after 1962 the milling of ore was completed with uranium extraction using chemical processes (acid and alkaline leach technologies) based on the operating conditions recommended by the international organizations. In total, the uranium ore was mined from five mine pits which produced five spoil deposits. In 1997, the mine was closed due to being uneconomical and in 1998, the clean-up of the uranium mining legacy started [32]. Figure 1 shows the location of the study area, spoil deposit No. 1, and the distribution of gamma activity on its surface.

\section{Meteorological conditions}

The meteorological data were retrieved from the data published on the website [33] of the Hungarian Central Statistical Office. During the remediation period, from the time when the mine closed to sampling of soil (1997-2018), the average precipitation was $674 \mathrm{~mm}$ with a minimum of $405 \mathrm{~mm}$ in 2011 and the maximum of $981 \mathrm{~mm}$ in 2014. During the sampling month of July 2018, the precipitation intensity was $58 \mathrm{~mm}$ over thirteen precipitation days, the days with wind greater than or equal to $10 \mathrm{~m} / \mathrm{s}$ were eleven as 
indicated on the website [34]. It should be noted that in 2018, the highest precipitation intensity (134 mm) was observed in June, while sampling took place in July.

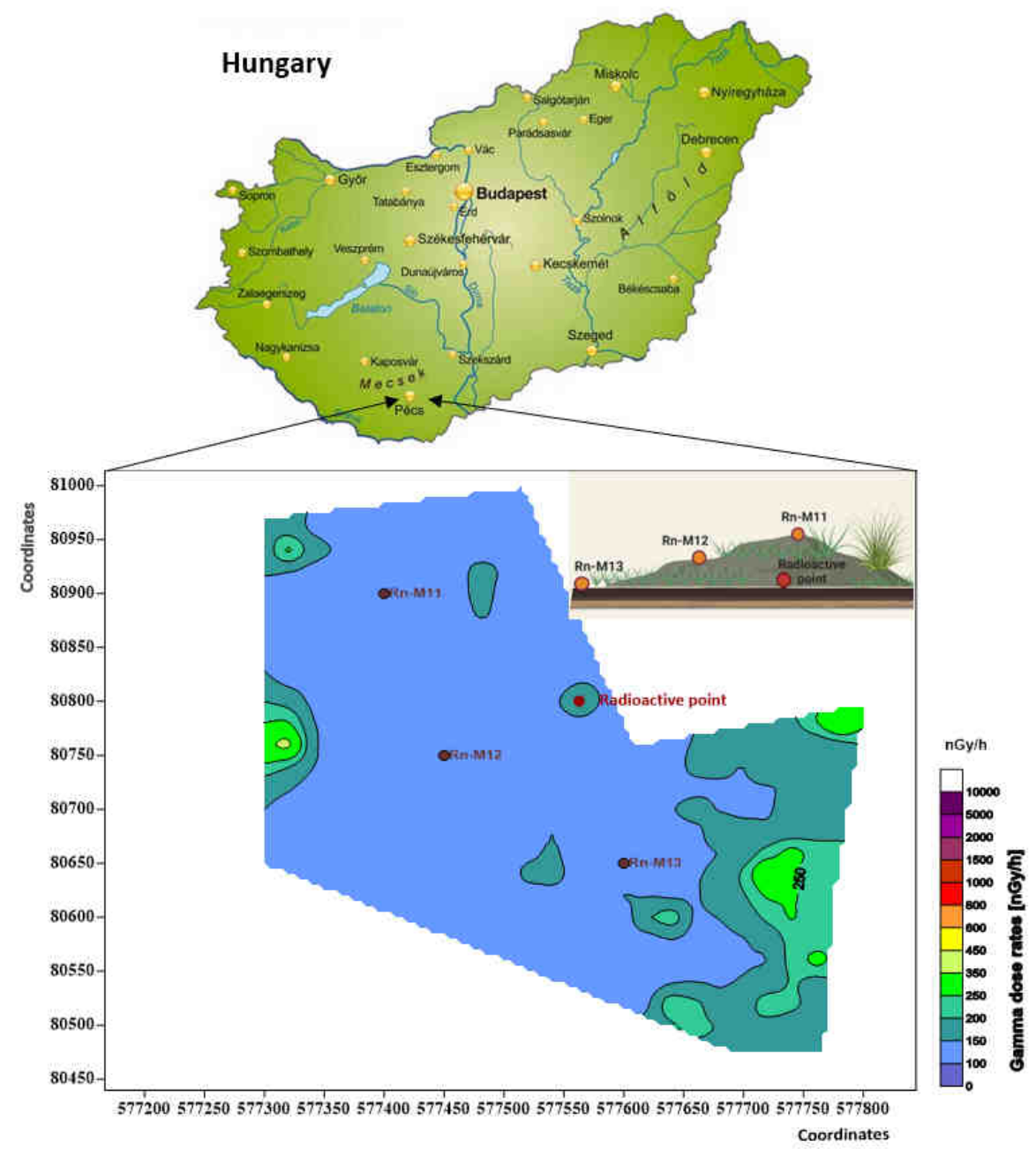

Fig. 1. Site location map of Hungary downloaded from OrangeSmile.com [35] and map of Mecsek uranium mine spoil deposit No. 1, Pecs (2017) indicating soil sampling locations and the gamma dose rates distribution with an insert of spoil deposit No. 1 schematic diagram

\section{Soil sampling}

Four sampling locations were selected from the soil covering the Mecsek uranium spoil deposit No. 1 in Pecs, South-west of Hungary. The sampling locations were selected based on the topographic details of the spoil deposit. Samples were collected from the top of the deposit - Rn-M11, on the slope of the deposit - Rn-M12, at the bottom field $\mathrm{Rn}-\mathrm{M} 13$, and at the bottom edge of the slope of the deposit - Radioactive sample (RA). As part of the monitoring program, Mecsek uranium mine routinely measures the gamma dose 
rate in $\mathrm{nGy} / \mathrm{h}$ to have an indication about the level of radioactivity emanating from natural radionuclides as indicated in Figure 1. The location where the RA sample was collected was chosen based on the knowledge of its high gamma dose rate (ranging between 150 and $200 \mathrm{nGy} / \mathrm{h}$ ) as compared to other sampling locations where the gamma dose rate was lower ranging from 100 and $150 \mathrm{nGy} / \mathrm{h}$. This was done to evaluate if the PTE mobility behaviour would be different if the samples were collected from a location with an elevated radioactivity. Soil samples were collected using a hand auger instrument. Each soil core sample was taken from four different depths: 0-25 cm, 25-50 cm, $50-75 \mathrm{~cm}$, and $75-100 \mathrm{~cm}$. The sample at depth 75-100 cm for sample location Rn-M11 could not be sampled because there were hard rocks underneath the soil. The same situation was experienced with the RA soil sample; therefore, it could only be sampled from $0-25 \mathrm{~cm}$ depth.

\section{Soil chemical analysis and sample preparation}

The soil samples were air-dried and grinded using Retch SM 100 with a $0.25 \mathrm{~mm}$ sieve instrument. The samples were analysed for parameters such as $\mathrm{pH}$ and CEC. All reagents used were analytical-reagent grade.

\section{The soil $p H$}

The soil $\mathrm{pH}$ was measured in $1 \mathrm{M} \mathrm{KCl}$ solution using a 1:2.5 soil to $\mathrm{KCl}$ solution ratio, with the aid of a Glass-electrode $\mathrm{pH}$ meter. Ten grams of homogenised soil was weighed into centrifuge tubes and $25 \mathrm{~mL}$ of $1 \mathrm{~mol} / \mathrm{l} \mathrm{KCl}$ added to it. This could stand for 1 hour and shaken occasionally. Following this, the electrodes of the $\mathrm{pH}$ meter were inserted into the partly settled suspension and the $\mathrm{pH}$ measured.

\section{The soil cation exchange capacity (CEC)}

The soil CEC was measured using $0.1 \mathrm{M} \mathrm{BaCl}_{2}$ solution in duplicate according to the Hungarian Standard MSZ 1484-3: 2006 [36]. Four grams of each homogenized soil sample were weighed into $50 \mathrm{~mL}$ polycarbonate centrifuge tubes, $40 \mathrm{~mL}$ of $0.1 \mathrm{M} \mathrm{BaCl}_{2}$ solution was added to it. The samples were shaken on a Yellowline OS 5 Basic Orbital Shaker at 560 rotation per minute (rpm) speed for 2 hours. The samples were centrifuged for 10 minutes at $5000 \mathrm{rpm}$, filtered using Munktell filter paper grade $389(90 \mathrm{~mm})$, and $\mathrm{Ba}$ concentration was measured using a HORIBA Jobin Yvon ACTIVA M Inductively Coupled Plasma - Optical Emission Spectrometer (ICP-OES). The CEC was calculated from the Ba concentration. The ICP-OES instrument was optimised for calibration and operated using the parameters described in detail by Heltai et al. [18]. The instrumental operating conditions were as follows: Incident RF-power - $1200 \mathrm{~W}$; Outer gas flow (Argon) - $15.94 \mathrm{~L} / \mathrm{min}$; Sheath gas flow (Argon) - $0.3 \mathrm{~L} / \mathrm{min}$; Auxiliary gas flow (Argon) $0.6 \mathrm{~L} / \mathrm{min}$; Nebuliser gas pressure (Argon) - 2.86 bar; Nebuliser solution uptake (Meinhardt-cyclonic spray chamber) $-0.85 \mathrm{~mL} / \mathrm{min}$.

\section{Fractionation of soil PTE by BCR sequential extraction}

Homogenised soil samples were subjected to the modified three-step BCR sequential extraction procedure with an additional $(+1)$ aqua regia step by Rauret et al. $[13,16]$ which is adapted from Tessier et al. [37]. Three independent replicates were performed for soil samples collected at 0-25 cm depths for each sample and the blanks were measured in 
parallel for each set of analyses. The Certified Reference Material (CRM) BCR ${ }^{\circledR}-701$ for $\mathrm{Cd}, \mathrm{Cr}, \mathrm{Cu}, \mathrm{Ni}, \mathrm{Pb}$, and $\mathrm{Zn}$ was prepared in parallel with the samples to control the accuracy of the analysis. From the extracts prepared by the procedure in Table 1 as described in detail by Rauret et al. [13, 16] and Heltai et al. [18], ten elements (Cd, Co, Cr, $\mathrm{Cu}, \mathrm{Fe}, \mathrm{Mn}, \mathrm{Ni}, \mathrm{Pb}, \mathrm{U}$, and $\mathrm{Zn}$ ) were determined by the ICP-OES instrument using the same operating conditions as used for the CEC.

Table 1

The BCR sequential extraction procedure

\begin{tabular}{|c|c|c|}
\hline Extraction step & Extractant reagents & Element fraction \\
\hline Fraction 1 & $0.11 \mathrm{M}$ acetic acid & Exchangeable and Acid-soluble fraction \\
\hline Fraction 2 & $\begin{array}{c}0.5 \mathrm{M} \mathrm{NH}_{2}-\mathrm{OH} \cdot \mathrm{HCl} \text { (adjusted to } \\
\left.\mathrm{pH}=1.5 \text { by adding } 25 \mathrm{~mL} 2 \mathrm{M} \mathrm{HNO}_{3}\right)\end{array}$ & $\begin{array}{c}\text { Reducible species (e.g., Fe and Mn oxides, } \\
\text { oxyhydroxides) }\end{array}$ \\
\hline Fraction 3 & $\begin{array}{c}\text { preliminary oxidation by } 8.8 \mathrm{M} \mathrm{H}_{2} \mathrm{O}_{2}, \\
\text { then } 1 \mathrm{M} \mathrm{NH}_{4} \mathrm{OAc}(\mathrm{pH}=2)\end{array}$ & $\begin{array}{c}\text { Oxidizable }- \text { forms bound to organic matter or } \\
\text { sulphides }\end{array}$ \\
\hline Fraction 4 & $\begin{array}{c}\mathrm{HNO}_{3} / \mathrm{H}_{2} \mathrm{O}_{2} \\
\text { (microwave supported acid digestion) }\end{array}$ & Residual fraction, non-silicate bound metals \\
\hline
\end{tabular}

\section{Quality control}

The quality control for this study was conducted using the CRM BCR ${ }^{\circledR}-701$. This CRM is certified for only six elements $(\mathrm{Cd}, \mathrm{Cr}, \mathrm{Cu}, \mathrm{Ni}, \mathrm{Pb}$, and $\mathrm{Zn}$ ). The recoveries [\%] for each of the certified elements were calculated. Additionally, the cumulated concentrations of fractions $(F 1+F 2+F 3+F 4)$ were compared to the pseudo total concentrations are given in $\mathrm{mg} / \mathrm{kg}$ units.

\section{Statistical analysis}

The statistical analysis was performed using Microsoft Excel 2010. Descriptive statistics were used to determine whether the data distribution would be normal or non-normal for the $\mathrm{pH}$ and CEC. To determine the common characteristics of the PTEs and chemical properties in the soil, the Pearson's correlation coefficient $(r)$ analysis was performed. The $r$-value is normally employed to find the relationship between two variables [38]. The $t$ statistics were also conducted to verify the significance of possible differences between PTE concentrations, $\mathrm{pH}$, and CEC in the soil at a $95 \%$ confidence level.

\section{Determination of the mobility factor}

The mobility factors, $M F$, of the PTEs were calculated using the equation:

$$
M F=\frac{F 1+F 2+F 3}{F 1+F 2+F 3+F 4} \cdot 100
$$

where $F$ is Fraction 1 - acid-soluble, Fraction 2 - reducible, Fraction 3 - oxidizable, and Fraction 4 - residual [12, 14, 21, 23, 39].

\section{Results and discussion}

\section{Chemical properties}

The $\mathrm{pH}$ and the CEC of the studied soil are presented in Table 2 and in Figure A-1 of the supplementary material. The data indicated that the range of $\mathrm{pH}$ values across the entire study area was narrow, ranging between 5.17 and 6.42 , these values classify these soils as 
acidic. The CEC data resulted in a wide range from 8.23 to $52.9 \mathrm{cmol}(+) / \mathrm{kg}$. This could be due to different soil types that were used to cover the soil of the spoil deposit. According to Hasegawa et al. [40], the CEC for clay soils usually exceeds $30 \mathrm{cmol}(+) / \mathrm{kg}$ whereas, for sandy soils, the value ranges from 0 to $5 \mathrm{cmol}(+) / \mathrm{kg}$. These results are in correlation with the results obtained from several studies conducted from the uranium polluted soils where the CECs had wide ranges 4.10 to $81.4 \mathrm{cmol}(+) / \mathrm{kg}$ [41], 51.0 to $658 \mathrm{meq} / \mathrm{kg}$ [42], 0.12 to $5.13 \mathrm{cmol}(+) / \mathrm{kg}$ [43], and 8.40 to $59.0 \mathrm{cmol}(+) / \mathrm{kg}$ [44]. The average CEC values for each sample ranged from 24.6 to $31.2 \mathrm{cmol}(+) / \mathrm{kg}$ and there was no indication of any trend, whereas the $\mathrm{pH}$ values followed a decreasing trend from the top of the mine deposit to the bottom of the mine deposit. The highest average $\mathrm{pH}$ value was recorded for the sample collected on top of the deposit (Rn-M11) at 6.17, and the lowest $\mathrm{pH}$ value was recorded from the sample collected from the bottom of the deposit (RA sample) at 5.27. Rn-M12 at 25-50 cm depth had the lowest CEC of $8.25 \mathrm{cmol}(+) / \mathrm{kg}$ which is an indication that the soil at this sampling location is more susceptible to cation nutrient loss through leaching. The normality determination resulted in skewness and kurtosis to be within the accepted threshold of \pm 2 which suggests normal distribution [45].

Table 2

Descriptive statistics for the average values for selected soil properties

\begin{tabular}{|c|c|c|c|}
\hline \multirow{2}{*}{ Sample } & $\begin{array}{c}\text { Soil depth } \\
{[\mathbf{c m}]}\end{array}$ & CEC [cmol(+)/kg] & pH [-] \\
\hline \multirow{3}{*}{ Rn-M11 } & $0-25$ & 52.89 & 6.42 \\
\cline { 2 - 4 } & $25-50$ & 20.17 & 6.22 \\
\cline { 2 - 4 } & $50-75$ & 14.55 & 5.87 \\
\hline \multirow{4}{*}{ Rn-M12 } & $0-25$ & 32.96 & 5.67 \\
\cline { 2 - 4 } & $25-50$ & 8.23 & 5.40 \\
\cline { 2 - 4 } & $50-75$ & 24.42 & 5.36 \\
\cline { 2 - 4 } & $75-100$ & 32.96 & 5.42 \\
\hline \multirow{4}{*}{ Rn-M13 } & $0-25$ & 28.15 & 5.64 \\
\cline { 2 - 4 } & $25-50$ & 31.83 & 5.17 \\
\cline { 2 - 4 } & $50-75$ & 28.08 & 5.37 \\
\cline { 2 - 4 } RA sample & $75-100$ & 36.61 & 5.44 \\
\hline \multicolumn{2}{|c|}{ Mean* } & 27.26 & 5.27 \\
\hline \multicolumn{2}{|c|}{ Standard deviation } & 28.18 & 5.60 \\
\hline \multicolumn{2}{|c|}{ Standard error } & 11.30 & 0.39 \\
\hline \multicolumn{2}{|c|}{ Skewness } & 3.26 & 0.11 \\
\hline \multicolumn{2}{|c|}{ Kurtosis } & 0.37 & 1.20 \\
\hline
\end{tabular}

* There was no significant difference among all four samples at $95 \%$ confidence level

\section{Fractionation of soil PTE content}

In Table A-1 (supplementary material), the concentration of $\mathrm{Cd}, \mathrm{Co}, \mathrm{Cr}, \mathrm{Cu}, \mathrm{Fe}, \mathrm{Mn}$, $\mathrm{Ni}, \mathrm{Pb}, \mathrm{U}$, and $\mathrm{Zn}$ in fractions $F 1, F 2, F 3$, and $F 4$ and their cumulated concentrations of fractions of $(F 1+F 2+F 3+F 4)$, and the pseudo total concentrations are given in $\mathrm{mg} / \mathrm{kg}$ units. In the first column, the detection limits of elements are given in $\mathrm{mg} / \mathrm{kg}$ units for the applied ICP-OES methods. The percentage recovery for each element was also calculated and the results are indicated in Table A-2 (supplementary material). 
The average percentage distribution of PTE concentrations for each sample in different fractions of modified BCR is represented graphically in Figure 2. The results are discussed for each element.

a)

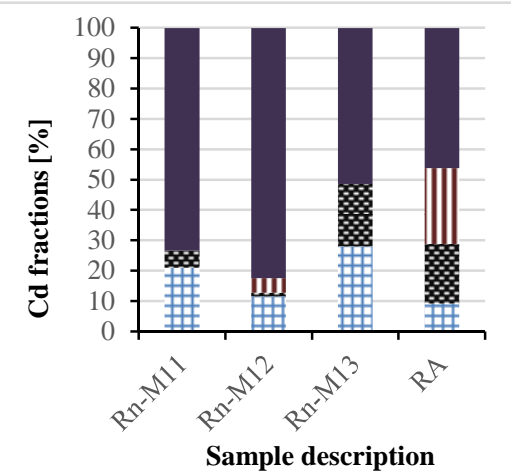

c)

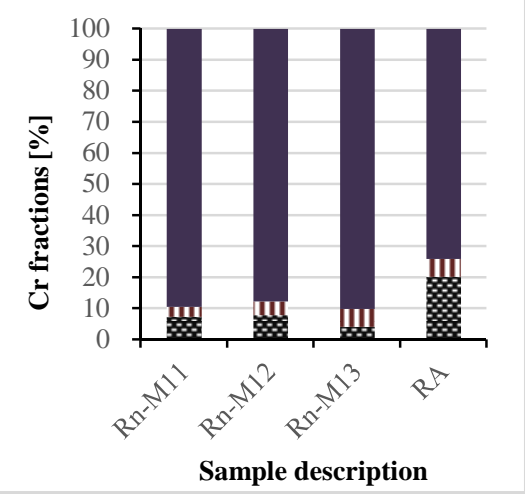

e)

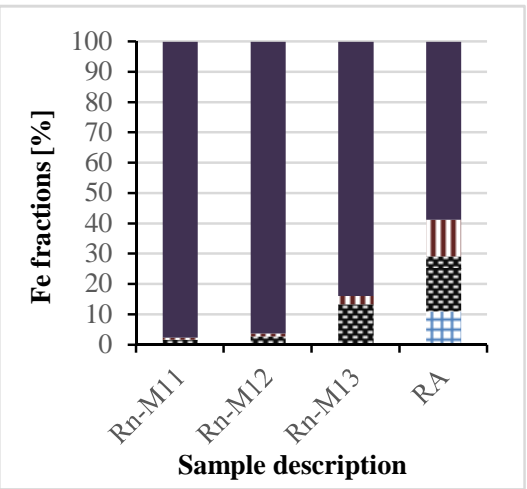

b)

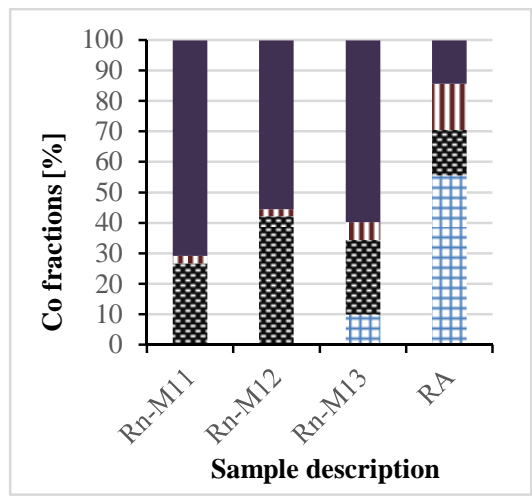

d)

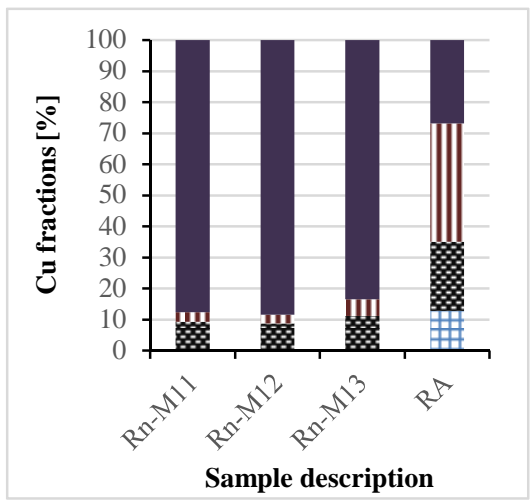

f)

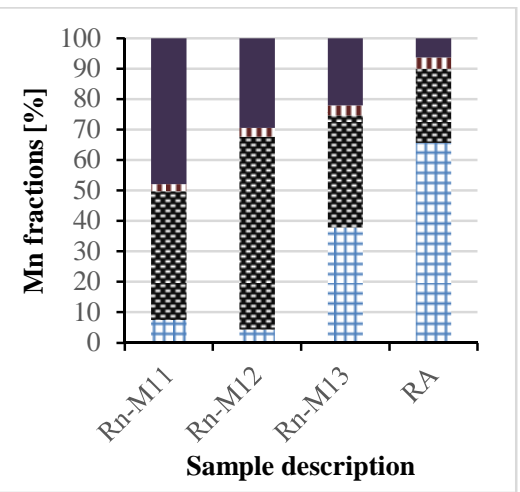


g)

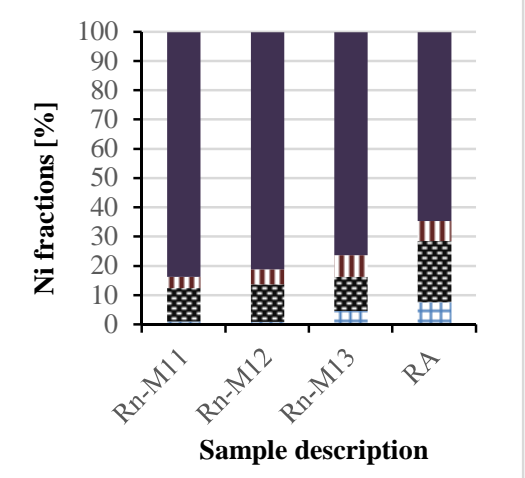

i)

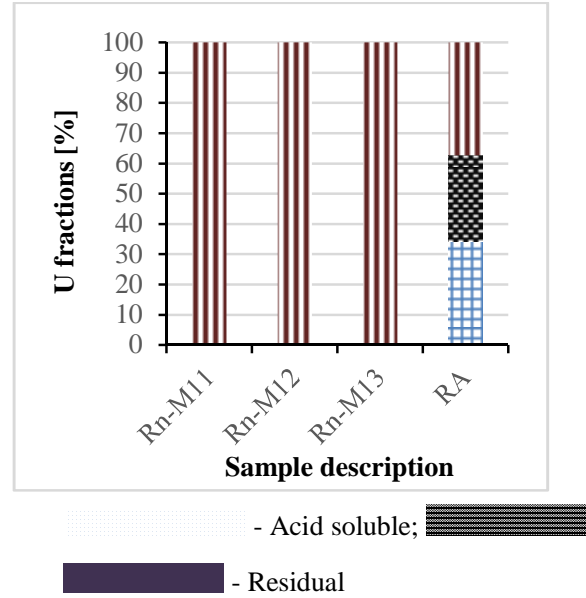

h)

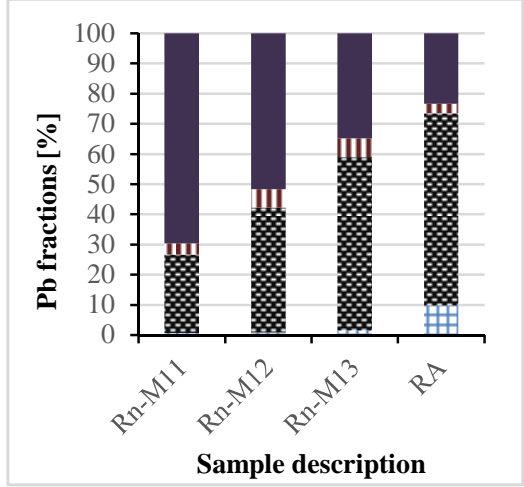

j)

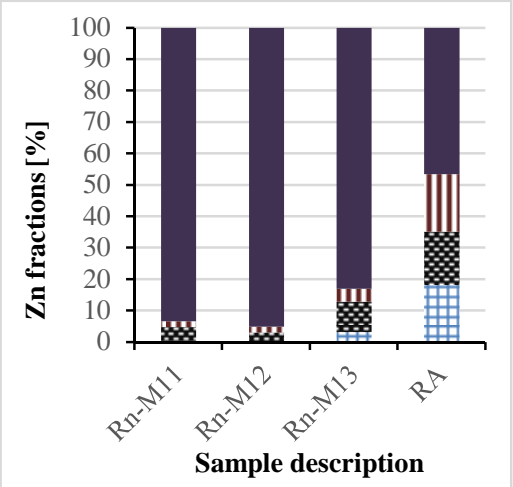

- Reducible;

Fig. 2 The average percentages for fraction distribution $(F 1, F 2, F 3$, and $F 4)$ of extractable content [\%] of: a) $\mathrm{Cd}$, b) $\mathrm{Co}$, c) $\mathrm{Cr}$, d) $\mathrm{Cu}$, e) $\mathrm{Fe}$, f) $\mathrm{Mn}, \mathrm{g}$ ) $\mathrm{Ni}, \mathrm{h}$ ) $\mathrm{Pb}$, i) $\mathrm{U}$ and j) $\mathrm{Zn}$ in soil from uranium mine spoil bank

\section{Potential mobility of PTEs in soil}

The fractions weakly bound to soil components (acid-soluble, reducible, and oxidizable) were used to assess the mobility of elements in soil [22]. The mobility factor was calculated, and the results are illustrated in Figure 3. The results indicated that in samples the mobility of PTEs was in the following order:

$\mathrm{Rn}-\mathrm{M} 11: \mathrm{U}>\mathrm{Mn}>\mathrm{Pb}>\mathrm{Co}>\mathrm{Cd}>\mathrm{Ni}>\mathrm{Cu}>\mathrm{Cr}>\mathrm{Zn}>\mathrm{Fe}$,

$\mathrm{Rn}-\mathrm{M} 12: \mathrm{U}>\mathrm{Mn}>\mathrm{Pb}>\mathrm{Co}>\mathrm{Ni}>\mathrm{Cd}>\mathrm{Cr}>\mathrm{Cu}>\mathrm{Zn}>\mathrm{Fe}$,

$\mathrm{Rn}-\mathrm{M} 13: \mathrm{U}>\mathrm{Mn}>\mathrm{Pb}>\mathrm{Cd}>\mathrm{Co}>\mathrm{Ni}>\mathrm{Zn}>\mathrm{Cu}>\mathrm{Fe}>\mathrm{Cr}$, and

$\mathrm{RA}: \mathrm{U}>\mathrm{Mn}>\mathrm{Co}>\mathrm{Pb}>\mathrm{Cu}>\mathrm{Cd}>\mathrm{Zn}>\mathrm{Fe}>\mathrm{Ni}>\mathrm{Cr}$.

The mobility order for all the samples asserts that $\mathrm{U}$ followed by $\mathrm{Mn}$ and $\mathrm{Pb}$ were highly mobile in this study, while $\mathrm{Fe}, \mathrm{Zn}$, and $\mathrm{Cr}$ were less mobile. This data reveals that $\mathrm{Cd}, \mathrm{Mn}, \mathrm{Pb}$, and $\mathrm{U}$ are more available for mobility compared to other PTEs in this study. Based on previous studies, sequential extractions revealed that a significant fraction of $U$ 
and possibly $\mathrm{Pb}$ and $\mathrm{Cd}$ could be considered as mobile [46]. The high mobility of $\mathrm{U}$ might be coming from the wounding that occurred during the remediation process the spoil deposit No. 1. Under normal circumstances, $\mathrm{Cd}$ is usually more mobile than $\mathrm{Pb}$. However natural radioactive elements such as uranium break down and form lead as one of their end products [47]. This explains the reason $\mathrm{Pb}$ was found to be more mobile after $\mathrm{U}$ and $\mathrm{Mn}$.

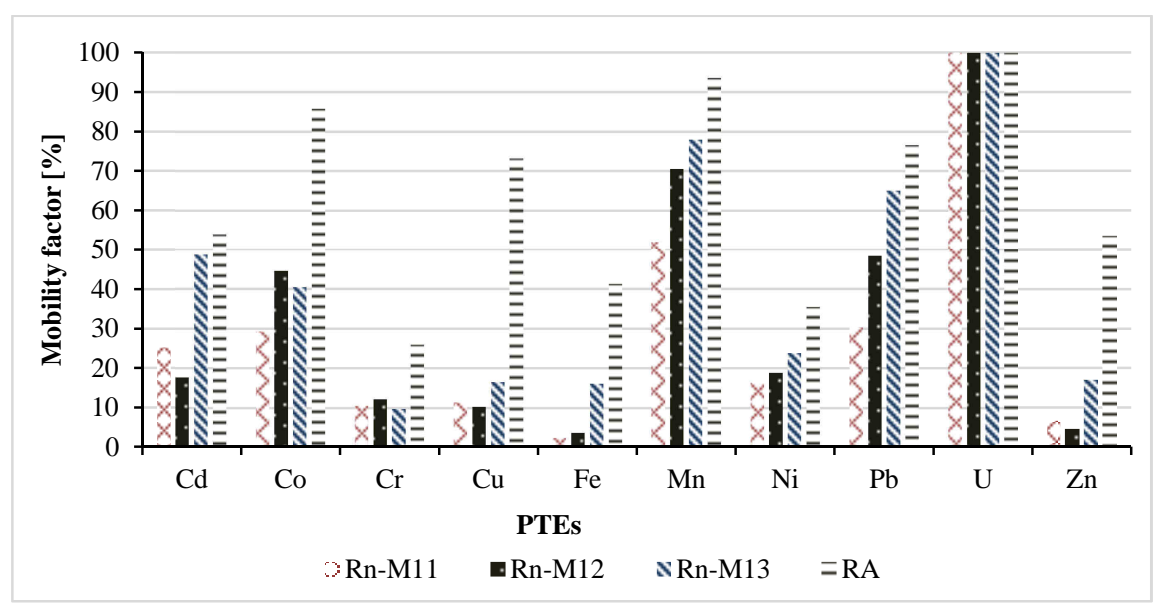

Fig. 3. Potential mobility of PTEs in each soil sample

\section{Correlation coefficient analysis}

Pearson's correlation coefficients of the PTEs were calculated from the average concentrations of each sample to establish inter-relationships of elements and chemical properties in the soil samples. The results of the correlation matrix are presented in Table 3.

Table 3

Correlation matrix ( $r$ ) for the concentrations of the PTEs and the chemical properties of the soil

\begin{tabular}{|c|c|c|c|c|c|c|c|c|c|c|c|c|}
\hline & $\mathbf{C d}$ & $\mathbf{C o}$ & $\mathbf{C r}$ & $\mathbf{C u}$ & $\mathbf{F e}$ & $\mathbf{M n}$ & $\mathbf{N i}$ & $\mathbf{P b}$ & $\mathbf{U}$ & $\mathbf{Z n}$ & pH & CEC \\
\hline $\mathbf{C d}$ & $\mathbf{1 . 0 0 0}$ & & & & & & & & & & & \\
\hline $\mathbf{C o}$ & $\mathbf{- 0 . 6 7 4}$ & $\mathbf{1 . 0 0 0}$ & & & & & & & & & & \\
\hline $\mathbf{C r}$ & 0.498 & 0.024 & $\mathbf{1 . 0 0 0}$ & & & & & & & & & \\
\hline $\mathbf{C u}$ & $\mathbf{0 . 9 9 7}$ & $\mathbf{- 0 . 7 2 3}$ & 0.451 & $\mathbf{1 . 0 0 0}$ & & & & & & & & \\
\hline $\mathbf{F e}$ & $\mathbf{- 0 . 9 1 4}$ & $\mathbf{0 . 9 1 6}$ & -0.242 & $\mathbf{- 0 . 9 4 0}$ & $\mathbf{1 . 0 0 0}$ & & & & & & & \\
\hline $\mathbf{M n}$ & $\mathbf{- 0 . 9 8 2}$ & 0.562 & -0.651 & $\mathbf{- 0 . 9 6 8}$ & $\mathbf{0 . 8 4 0}$ & $\mathbf{1 . 0 0 0}$ & & & & & & \\
\hline $\mathbf{N i}$ & -0.299 & $\mathbf{0 . 6 2 9}$ & $\mathbf{0 . 6 7 7}$ & -0.351 & 0.524 & 0.114 & $\mathbf{1 . 0 0 0}$ & & & & & \\
\hline $\mathbf{P b}$ & $\mathbf{0 . 9 9 6}$ & $\mathbf{- 0 . 6 6 3}$ & 0.563 & $\mathbf{0 . 9 9 2}$ & $\mathbf{- 0 . 9 0 4}$ & $\mathbf{- 0 . 9 9 1}$ & -0.227 & $\mathbf{1 . 0 0 0}$ & & & & \\
\hline $\mathbf{U}$ & $\mathbf{0 . 9 9 1}$ & $\mathbf{- 0 . 7 3 2}$ & 0.524 & $\mathbf{0 . 9 9 3}$ & $\mathbf{- 0 . 9 3 9}$ & $\mathbf{- 0 . 9 7 5}$ & -0.270 & $\mathbf{0 . 9 9 5}$ & $\mathbf{1 . 0 0 0}$ & & & \\
\hline $\mathbf{Z n}$ & $\mathbf{- 0 . 7 0 1}$ & $\mathbf{0 . 6 9 3}$ & $\mathbf{- 0 . 6 6 9}$ & $\mathbf{- 0 . 7 0 9}$ & $\mathbf{0 . 7 4 8}$ & $\mathbf{0 . 7 3 6}$ & -0.109 & $\mathbf{- 0 . 7 5 0}$ & $\mathbf{- 0 . 7 8 6}$ & $\mathbf{1 . 0 0 0}$ & & \\
\hline $\mathbf{p H}$ & $\mathbf{- 0 . 6 5 4}$ & $\mathbf{0 . 9 6 5}$ & 0.208 & $\mathbf{- 0 . 7 0 6}$ & $\mathbf{0 . 8 9 1}$ & 0.512 & $\mathbf{0 . 8 0 6}$ & $\mathbf{- 0 . 6 2 1}$ & $\mathbf{- 0 . 6 8 3}$ & 0.500 & $\mathbf{1 . 0 0 0}$ & \\
\hline $\mathbf{C E C}$ & -0.257 & $\mathbf{0 . 8 6 1}$ & 0.511 & -0.325 & $\mathbf{0 . 6 1 8}$ & 0.093 & $\mathbf{0 . 8 1 2}$ & -0.224 & -0.309 & 0.290 & $\mathbf{0 . 8 9 7}$ & $\mathbf{1 . 0 0 0}$ \\
\hline & $\mathbf{C d}$ & $\mathbf{C o}$ & $\mathbf{C r}$ & $\mathbf{C u}$ & $\mathbf{F e}$ & $\mathbf{M n}$ & $\mathbf{N i}$ & $\mathbf{P b}$ & $\mathbf{U}$ & $\mathbf{Z n}$ & $\mathbf{p H}$ & $\mathbf{C E C}$ \\
\hline
\end{tabular}

Values highlighted in bold are significant at $95 \%$ confidence level; $p \leq 0.05$

The outcome of the correlation relationship conducted between the $\mathrm{pH}$ and the CEC of the soil indicated that there is a strong relationship $(r=0.897, p \leq 0.05)$ between the two 
variables. When the $r$-value is close to 1 , it is considered that the two variables have a strong relationship and $p \leq 0.05$ state that there is sufficient evidence to conclude that the correlation coefficient is significantly different from zero and therefore reject the null hypothesis $[48,49]$.

The results indicated that $\mathrm{pH}$ had a strong correlation with $\mathrm{Co}(r=0.965), \mathrm{Fe}$ $(r=0.891)$, and $\mathrm{Ni}(r=0.806)$ at $p \leq 0.05$; a moderate correlation with $\mathrm{Mn}(r=0.512)$ and $\mathrm{Zn}(r=0.500)$ at $p>0.05$; a low correlation with $\mathrm{Cr}(r=0.208, p>0.05)$; and a negative correlation with $\mathrm{Cd}, \mathrm{Cu}, \mathrm{Pb}$ and $\mathrm{U}$ at $p \leq 0.05$. The $\mathrm{CEC}$ had a strong correlation with $\mathrm{Ni}$ $(r=0.812)$, $\mathrm{Co}(r=0.861)$ at $p \leq 0.05$; a moderate correlation with $\mathrm{Cr}(r=0.511, p>0.05)$ and $\mathrm{Fe}(r=0.618, p \leq 0.05)$; a low correlation with $\mathrm{Zn}(r=0.290)$ and $\mathrm{Mn}(r=0.093)$ at $p>0.05$; and a negative correlation with $\mathrm{Cd}, \mathrm{Cu}, \mathrm{Pb}$, and $\mathrm{U}$ at $p>0.05$. The correlation of the $\mathrm{pH}, \mathrm{CEC}, \mathrm{Co}, \mathrm{Ni}$ and $\mathrm{Fe}$ was demonstrated by the behaviour of these elements. When the $\mathrm{pH}$ and CEC decreased, these elements were increasing in the non-residual fractions.

There was a very strong relationship among $\mathrm{Cd}, \mathrm{Cr}, \mathrm{Pb}, \mathrm{U}$, and $\mathrm{Cu}$ at $p \leq 0.05$. Consequently, the null hypothesis which states that there is no relationship between the two variables was rejected. It should be noted that $\mathrm{Cd}, \mathrm{Cr}, \mathrm{Pb}$, and $\mathrm{U}$ are non-essential elements that are considered toxic even in small quantities, whereas $\mathrm{Cu}$ is an essential element that is required by the plant in small quantities [50-52]. The pairs $\mathrm{Cd}-\mathrm{Cu}(r=0.997), \mathrm{Cd}-\mathrm{Pb}$ $(r=0.996), \mathrm{Cd}-\mathrm{U}(r=0.991), \mathrm{Cu}-\mathrm{Pb}(r=0.992), \mathrm{Cu}-\mathrm{U}(r=0.993), \mathrm{Pb}-\mathrm{U}(r=0.995)$ at $p \leq 0.05$ had a strongly correlation which might be an indication that these elements may be from anthropogenic conditions could be the common factor among these elements. These results imply that where $\mathrm{U}$ is mobile, there is a high possibility that $\mathrm{Cd}, \mathrm{Cu}$, and $\mathrm{Pb}$ will also be available. This has been demonstrated by the RA sample where $100 \%$ of U was bound to all the non-residual fractions. Similarly, $\mathrm{Cd}(53.9 \%), \mathrm{Cu}(73.2 \%)$, and $\mathrm{Pb}$ (76.6 \%) including Co (85.7\%), Mn (93.6 \%), Zn (53.4\%) in RA sample were in abundance in the non-residual fractions. There was a strong relationship among the samples regarding the distribution of PTEs, with all having an $r$-value above 0.999 at $p \leq 0.05$.

\section{Discussion of PTE distribution}

According to our former study, the pseudo-total concentrations of PTEs were low and below the health-threshold limits (except in one case Cr) [27], their distribution among the fractions can draw attention to potential release to the environment through the covering soil in the present situation.

Cadmium: The results indicate that the concentration of $\mathrm{Cd}$ for all the analysed samples was lower than the acceptable threshold values [39]. Different distribution patterns in all four samples were observed. The most amount of $\mathrm{Cd}$ was associated with the residual fraction in Rn-M11 and Rn-M12, whereas the substantial amount of Cd associated with the non-residual fractions in Rn-M13 and RA samples simply shows that $\mathrm{Cd}$ may result in a transfer into water [39] and may easily be available for plant uptake. The reason for these observations might be the lower $\mathrm{pH}$ associated with these two samples and their topographic positions.

Cobalt: The dominant portion of Co was found in a residual fraction with a fraction distribution followed by the reducible fraction. These results indicate that there is a high possibility for a Co element to be mobile with a slight change of environmental conditions. This is confirmed by the RA sample where the distribution average in non-residual fractions was 85.7. This might be due to anthropogenic activities where the RA sample was collected since it indicated anomalous behaviour as indicated in Figure 1. 
Chromium: A major portion of $\mathrm{Cr}$ was found in the residual fraction. This indicates that $\mathrm{Cr}$ strongly associated with the insoluble fraction and stable with lower transfer potential under anthropogenic conditions [14]. These results are in agreement with studies conducted by Pradhanang [53] and Pavlovic et al. [14], while Perez-Moreno et al. [54] indicated that $\mathrm{Cr}$ was mainly available in the oxidizable fraction of the organic matter that increases the solubility and mobility of $\mathrm{Cr}$ (III) and thus facilitates its oxidation [54].

Copper: It was observed that $\mathrm{Cu}$ was in abundance in the residual fraction for Rn-M11, $\mathrm{Rn}-\mathrm{M} 12$, and Rn-M13, however in the RA sample, $\mathrm{Cu}$ was significantly less. According to Soltani et al. [55], $\mathrm{Cu}$ in the soil is strongly retained by the solid phases and is generally poorly soluble and not mobile owing to its ionic properties. It was also observed that in samples Rn-M11 and Rn-M12, Cu was not detected in the acid-soluble fraction, however, samples Rn-M13 and the RA sample contained this fraction. The anthropogenic activities, topographic position, and low $\mathrm{pH}$ of the samples might be the key factors in the behaviour of these two samples.

Iron: $\mathrm{Fe}$ and $\mathrm{Cu}$ exhibited similar fractional distribution behaviour. Just like $\mathrm{Cu}, \mathrm{Fe}$ was strongly associated with the residual fraction in Rn-M11, Rn-M12, and Rn-M13, whereas, in RA, the content of Fe was slightly less. In samples Rn-M11 and Rn-M12 the Fe content in the acid-soluble fraction was not detectable, however, the $\mathrm{Fe}$ content was detectable in samples Rn-M13 and RA. Based on the study conducted by Soltani et al. [55], it was concluded that $\mathrm{Fe}$ and $\mathrm{Cr}$ are the least mobile elements due to $\mathrm{Fe}$ and $\mathrm{Cr}$ being usually bound to clay minerals rather than Fe oxides and hydroxides in soils and sediments.

Manganese: The average percentage in the distribution process indicated that the highest Mn content was found in the reducible fraction. However, the fractional distribution of Mn was different for every sample. Rn-M11 and Rn-M12 samples contained the most Mn content in the reducible fraction, Rn-M13 sample indicated even distribution of Mn content in the acid-soluble and reducible fractions, and lastly, in RA sample, the Mn content was in abundance in the acid-soluble fraction. According to Pavlovic et al. [14], it is expected to find the highest $\mathrm{Mn}$ content in the reducible fraction due to manganese oxyhydroxides being a main target of the hydroxylammonium chloride reagent.

Nickel: Highest percentages of $\mathrm{Ni}$ content were displayed in the residual fraction of all samples. The second highest content of $\mathrm{Ni}$ was found in the reducible fraction. These results indicate that there is a possibility of $\mathrm{Ni}$ to be mobilised under similar conditions, however, a large amount will be bound to the soil. According to Barman et al. [56], the abundance of $\mathrm{Ni}$ in the residual fraction indicates that this element is held by the studied soil constituents; it exhibits low mobility and unavailability and is not accessible to the plant roots for absorption.

Lead: The higher percentage for $\mathrm{Pb}$ in the non-residual fraction was observed in the reducible fraction (Rn-M13, RA, Rn-M12 sample). On the other hand, in the Rn-M11 sample, the $\mathrm{Pb}$ was abundant in the residual fraction, which is an indication that this location poses less threat to $\mathrm{Pb}$ mobility as compared to other locations. The relatively high $\mathrm{Pb}$ percentage in the reducible fraction could be caused by its adsorption propensity to clay minerals [14]. These results are in agreement with the study conducted by Davidson et al. [57] and Pavlović et al. [14], where it was concluded that $\mathrm{Mn}$, together with $\mathrm{Pb}$ were mainly associated with the reducible material.

Uranium: The observations made were that $\mathrm{U}$ was not present in the residual fraction for all the samples and it was noticed that from Rn-M11, Rn-M12, and Rn-M13 samples were not extracted $U$ content in acid-soluble and reducible fractions, $100 \%$ was extracted 
in the oxidizable fraction. This is an indication that $U$ may be highly mobile. On the other hand, for the RA sample, $U$ was distributed among the acid-soluble $(34.3 \%)$, reducible (28.5\%), and oxidizable $(37.3 \%)$ fractions, and the sum of the extractable U concentrations were 20-50 times higher than in the above samples. It has been noted that all the $\mathrm{U}$ content was eluted in the first three fractions and there was no $\mathrm{U}$ left in a residual fraction. This is an indication that $U$ is very mobile under these conditions. The reason might be that the RA sample contained high concentrations of $U$ content which is highly mobile [26] and the fact that the RA sample had the lowest $\mathrm{pH}$ and the lowest CEC compared to all the samples. According to Korychenskyi et al. [58], a higher uranium content coupled with organic complexes in the oxidizable fraction is an indication that under normal conditions this fraction is insoluble in water and will be retained in the soil. Additionally, Uranium has a valence of $+\mathrm{VI}\left(\mathrm{UO}_{2}{ }^{2+}\right.$ uranyl ion), the most stable and mobile form in an oxidant soil environment [59]. In circumstances that oxidise uranyl ion and its complexes enough, uranium can migrate several kilometres from the source into altered rocks and precipitate it into uranium minerals [60].

Zinc: There was an abundance of $\mathrm{Zn}$ in the residual fraction for samples $\mathrm{Rn}-\mathrm{M} 11$, Rn-M12, and Rn-M13. However, in the RA sample, Zn was found in the non-residual fractions be $46.6 \%$. In the most mobile fraction - acid-soluble fraction, an increase of $\mathrm{Zn}$ was detected from top to bottom samples from 0.34 to $18.1 \%$. The anthropogenic conditions could have contributed to this behaviour and this may be due to RA and Rn-M13 samples having lower $\mathrm{pH}$ as compared to $\mathrm{Rn}-\mathrm{M} 11$ and $\mathrm{Rn}-\mathrm{M} 12$ samples. The greater percentage of $\mathrm{Zn}$ in the residual fraction indicates that in this study $\mathrm{Zn}$ was less mobile, and in this case, it poses a little risk to the environment [61]. Similar results were obtained by other studies where $\mathrm{Zn}$ was in abundance in the residual fraction [62-64]. Therefore, the authors concluded that the results revealed that the main proportion of $\mathrm{Zn}$ was bound in the crystals of minerals, and its ecological risk was relatively low.

The results indicated that the percentages of the extractable amount of $\mathrm{U}, \mathrm{Mn}, \mathrm{Pb}$, and $\mathrm{Cd}$ in the non-residual fractions were subsequently high. High percentages of these PTEs in mobile fractions might lead to the high bioavailability of these elements, leading to toxicity if not properly handled [38, 52, 61, 65-67]. The observation made was that most of the PTEs in the residual fraction followed either Rn-M11 > Rn-M12 > Rn-M13 > RA or Rn-M12 > Rn-M11 > Rn-M13 > RA descending orders, except in the case of Cr where the order was Rn-M13 > Rn-M11 > Rn-M12 > RA. This implies that RA had the highest quantity of PTEs bound to the non-residual fractions. The topographic conditions and the anthropogenic activities during the recultivation may have contributed to the amount of concentration found in these sample locations and the possible release to the environment. The RA sample which was sampled from the bottom of the spoil deposit, had lower $\mathrm{pH}$, low soil moisture (3.16 \%), lower CEC with a higher non-residual PTE distribution percentage, whereas the samples collected from the top of the deposit and on the slope showed slightly higher $\mathrm{pH}$, higher CEC, with less non-residual PTE distribution percentage. Furthermore, the study conducted by Khumalo et al. [27] indicated that the soil samples collected from the top of the deposit (Rn-M11) contained less average total concentration followed by the sample collected from the slope (Rn-M12) and the samples collected from the bottom of the deposit (Rn-M13 and RA) had the highest average total concentrations. This could be due to the PTEs being transported by the precipitation from the top of the deposit to the bottom of the deposit. Additionally, there was no trend in terms of depths, the pseudo-total PTE concentrations varied throughout different depths of each sample. 
This could be the results of different soil types that were used to form the soil cover layer of the spoil deposit in question [27]. It was also noted that the Rn-M13 sample had similar trends to the RA sample when it came to the distribution of elements except the Rn-M13 contained less concentration of $U$. The reason might be that both these samples were sampled at the bottom of the spoil deposit where the soil had elevated total concentrations of PTEs as per the study conducted by Khumalo et al. [27]. The results of this study are in agreement with numerous studies [14, 38, 68, 69]. Additionally, the PTEs that were bound to the non-residual fractions, suggest that they are primarily derived from anthropogenic inputs, while the PTEs in the residual fractions indicate that they are of lithogenic origin [39].

\section{Conclusion}

1. The high average percentage of $\mathrm{U}, \mathrm{Mn}$, and $\mathrm{Pb}$ and a high percentage of $\mathrm{U}, \mathrm{Mn}, \mathrm{Pb}$, and $\mathrm{Cd}$ in non-residual fractions indicates that there is a possibility being released may become a threat to the environment by subsequently becoming available to be taken up by plants $[14,54]$. Although these elements exhibit high percentages in non-residual fractions, a large part of these percentages come from the RA sample which is radioactive and highly contaminated with $\mathrm{U}$. Therefore, the location where RA was taken from should be considered as a potential hazard to the environment. The fractional distribution of the RA sample shows that the mobility, availability, and vertical transport of metals are surprisingly different [65].

2. Based on the statistical analysis, a significant correlation between the $\mathrm{pH}$ and the CEC existed, therefore, it was concluded that these soil chemical properties have an impact on each other. Additionally, the $\mathrm{pH}$ had a significant relationship with $\mathrm{Co}, \mathrm{Fe}$, and $\mathrm{Ni}$; and the $\mathrm{CEC}$ had a significant relationship with $\mathrm{Co}, \mathrm{Fe}$, and $\mathrm{Ni}$, whereas the relationship between the $\mathrm{CEC}$ and $\mathrm{Cr}$ was not significant. Furthermore, there was a very strong relationship among $\mathrm{Cd}, \mathrm{Cr}, \mathrm{Pb}, \mathrm{U}$, and $\mathrm{Cu}$ which is significant at a $95 \%$ confidence level. These results imply that where $\mathrm{U}$ is mobile, there is a high possibility that $\mathrm{Cd}, \mathrm{Cu}$, and $\mathrm{Pb}$ will also be available.

3. The $\mathrm{U}, \mathrm{Cd}, \mathrm{Co}, \mathrm{Mn}, \mathrm{Cu}, \mathrm{Mn}, \mathrm{Pb}$, and $\mathrm{Zn}$ fractional distribution in the RA sample indicate that some parts of the spoil deposit require additional steps to protect the environment. The results from the BCR sequential extraction have indicated that the current state of the soil cover layer is not enough for effective retardation of migration of PTEs. Additional soil cover is needed to ensure environmental safety. Therefore, as stated by Sungur et al. [38, 70] and Ma et al. [71], the BCR sequential extraction procedure has proven to be useful in providing information regarding the mobility and bioavailability of PTEs for the planning and management of recultivation applications.

4. As a summary it can be concluded that the BCR sequential extraction is an appropriate tool for the identification of leakages through the wounded remediation cover soil layer. In spite of the relatively low pseudo-total concentration of PTEs, the sequential extraction proves additional information on their mobility by water infiltration. These results confirm the previous establishment based on the measuring of pseudo total concentration and plant uptake [27]. 


\section{Acknowledgements}

This research is supported by Stipendium Hungaricum [Reg. No.: 238700], by the South African Department of Higher Education and Training and by the Higher Education Institutional Excellence Program [NKFIH-1159-6/2019] awarded by the Ministry for Innovation and Technology within the framework of water-related research of Szent István University. This research was also supported by the Ministry of Innovation and Technology within the framework of the Thematic Excellence Program 2020, Institutional Excellence Sub-Program (TKP2020-IKA-12) in the topic of water-related researches of the Hungarian University of Agriculture and Life Sciences.

\section{References}

[1] Carvalho FP, Oliveira JM, Malta M, Lemos ME. Radioanalytical assessment of environmental contamination around non-remediated uranium mining legacy site and radium mobility. J Radioanal Nucl Chem. 2014;299:119-25. DOI: 10.1007/s10967-013-2734-1.

[2] Fernández-Ondoño E, Bacchetta G, Lallena AM, Navarro FB, Ortiz I, Jiménez MN. Use of BCR sequential extraction procedures for soils and plant metal transfer predictions in contaminated mine tailings in Sardinia. J Geochemical Explor. 2017;172:133-41. DOI: 10.1016/j.gexplo.2016.09.013.

[3] Kabata-Pendias A. Soil-plant transfer of trace elements - An environmental issue. Geoderma. 2004;122:143-9. DOI: 10.1016/j.geoderma.2004.01.004.

[4] Valencia-Avellan M, Slack R, Stockdale A, Mortimer RJG. Effect of episodic rainfall on aqueous metal mobility from historical mine sites. Environ Chem. 2017;14:469-75. DOI: 10.1071/EN17133.

[5] Smičiklas I, Šljivić-Ivanović M. Radioactive Contamination of the Soil: Assessments of Pollutants Mobility with Implication to Remediation Strategies. In: Larramendy ML, Soloneski S, editors. Soil Contamination Current Consequences and Further Solutions. Rijeka, Croatia: InTech; 2016. DOI: 10.5772/62589.

[6] Greger M. Uptake of Nuclides by Plants. Stockholm, Sweden: 2004. Available from: https://inis.iaea.org/collection/NCLCollectionStore/_Public/35/080/35080548.pdf.

[7] Dowdall M, Standring W, Shaw G, Strand P. Will global warming affect soil-to-plant transfer of radionuclides? J Environ Radioact. 2008;99:1736-45. DOI: 10.1016/j.jenvrad.2008.06.012.

[8] Ogundiran MB, Osibanjo O. Mobility and speciation of heavy metals in soils impacted by hazardous waste. Chem Speciat Bioavailab. 2009;21:59-69. DOI: 10.3184/095422909X449481.

[9] Shiva Kumar D, Srikantaswamy S. Factors affecting on mobility of heavy metals in soil environment. Int J Sci Res Dev. 2014;2:201-3. Available from: http://www.ijsrd.com/articles/IJSRDV2I3073.pdf.

[10] Rodgers KJ, Hursthouse A, Cuthbert S. The potential of sequential extraction in the characterisation and management of wastes from steel processing: A prospective review. Int J Environ Res Public Health. 2015;12:11724-55. DOI: 10.3390/ijerph120911724.

[11] Hooda PS. Trace Elements in Soils. 1st ed. Chichester, West Sussex, United Kingdom: John Wiley Sons, Ltd; 2010. DOI: 10.13140/RG.2.1.3377.1123.

[12] Qasim B, Motelica-Heino M. Potentially toxic element fractionation in technosoils using two sequential extraction schemes. Environ Sci Pollut Res. 2014;21:5054-65. DOI: 10.1007/s11356-013-2457-4.

[13] Rauret G, López-Sánchez JF, Sahuquillo A, Rubio R, Davidson C, Ure A, et al. Improvement of the BCR three step sequential extraction procedure prior to the certification of new sediment and soil reference materials. J Environ Monit. 1999;1:57-61. DOI: 10.1039/a807854h.

[14] Pavlović D, Pavlović M, Čakmak D, Kostić O, Jarić S, Sakan S, et al. Fractionation, mobility, and contamination assessment of potentially toxic metals in urban soils in four industrial Serbian cities. Arch Environ Contam Toxicol. 2018;75:335-50. DOI: 10.1007/s00244-018-0518-x.

[15] Zhu X, Yang F, Wei C. Factors influencing the heavy metal bioaccessibility in soils were site dependent from different geographical locations. Environ Sci Pollut Res. 2015;22:13939-49. DOI: 10.1007/s11356-015-4617-1.

[16] Rauret G, López-Sánchez JF, Sahuquillo A, Rubio R, Davidson C, Ure A, et al. The certification of the extractable contents (mass fractions) of $\mathrm{Cd}, \mathrm{Cr}, \mathrm{Cu}, \mathrm{Ni} . \mathrm{Pb}$ and $\mathrm{Zn}$ in freshwater sediment following a sequential extraction procedure - BCR-701. Belgium: 2001. Available from: https://op.europa.eu/en/publication-detail/-/publication/02c41803-8f6d-41f2-a73d-c47225ff8c6e [accessed March 14, 2020]. 
[17] Filgueiras AV, Lavilla I, Bendicho C. Evaluation of distribution, mobility and binding behaviour of heavy metals in surficial sediments of Louro River (Galicia, Spain) using chemometric analysis: A case study. Sci Total Environ. 2004;330:115-29. DOI: 10.1016/j.scitotenv.2004.03.038.

[18] Heltai G, Győri Z, Fekete I, Halász G, Kovács K, Takács A, et al. Application of flexible multi-elemental ICP-OES detection in fractionation of potentially toxic element content of solid environmental samples by a sequential extraction procedure. Microchem J. 2019;149:104029. DOI: 10.1016/j.microc.2019.104029.

[19] Heltai G, Győri Z, Fekete I, Halász G, Kovács K, Takács A, et al. Longterm study of transformation of potentially toxic element pollution in soil/water/sediment system by means of fractionation with sequential extraction procedures. Microchem J. 2018;136:85-93. DOI: 10.1016/j.microc.2017.01.026.

[20] Cuvier A, Pourcelot L, Probst A, Prunier J, Le Roux G. Trace elements and Pb isotopes in soils and sediments impacted by uranium mining. Sci Total Environ. 2016;566-567:238-49. DOI: 10.1016/j.scitotenv.2016.04.213.

[21] Salbu B, Krekling T, Oughton DH. Characterisation of radioactive particles in the environment. Analyst. 1998;123:843-9. DOI: 10.1039/a800314i.

[22] Kabala C, Singh BR. Fractionation and mobility of copper, lead, and zinc in soil profiles in the vicinity of a copper smelter. J Environ Qual. 2001;30:485-92. DOI: 10.2134/jeq2001.302485x.

[23] Topcuoğlu B. Heavy metal mobility and bioavailability on soil pollution and environmental risks in greenhouse areas. Int J Adv Agric Environ Eng. 2016;3:208-13. DOI: 10.15242/IJAAEE.ER0416020

[24] Mecsekérc Zrt. Uranium Monitoring 2017. Available from: https://www.mecsekerc.hu/eng-uraniparimonitoring [accessed May 10, 2020].

[25] IAEA. Treatment of liquid effluent from uranium mines and mills - Report of a co-ordinated research project 1996-2000. Austria: 2004. Available from: https://wwwpub.iaea.org/MTCD/Publications/PDF/te_1419_web.pdf.

[26] Khumalo LHN, Heltai G, Horváth M. Mobility of radionuclides from the spoil deposit No.1 of the abandoned uranium mine in Pécs, Hungary. In: Světlík I, Povinec PP, Pachnerová Brabcová K, editors. 5th Int Conf Environ Radioactivity ENVIRA 2019: Variations of Environmental Radioniclides, Prague: Czech Technical University in Prague; 2019. DOI: 10.14311/ENVIRA.2019.

[27] Khumalo L, Heltai G, Horváth M. The migration of potentially toxic elements during the recultivation of the uranium mining deposit in Mecsek. Acta Hydrol Slovaca. 2020;20:210-7. DOI: 10.31577/ahs-2019-0020.02.0026.

[28] Kubová J, Matúš P, Bujdoš M, Hagarová I, Medved' J. Utilization of optimized BCR three-step sequential and dilute $\mathrm{HCl}$ single extraction procedures for soil-plant metal transfer predictions in contaminated lands. Talanta. 2008;75:1110-22. DOI: 10.1016/j.talanta.2008.01.002.

[29] Obrador A, Alvarez JM, Lopez-Valdivia LM, Gonzalez D, Novillo J, Rico MI. Relationships of soil properties with $\mathrm{Mn}$ and $\mathrm{Zn}$ distribution in acidic soils and their uptake by a barley crop. Geoderma. 2007;137:432-43. DOI: 10.1016/j.geoderma.2006.10.001.

[30] Bacon JR, Davidson CM. Is there a future for sequential chemical extraction? Analyst. 2008;133:25-46. DOI: $10.1039 / \mathrm{b} 711896 \mathrm{a}$.

[31] Juhasz L, Erdi-Krausz G. Consequences of the Hungarian Uranium Mining and Milling. In: Int Atomic Energy Agency. Proc Workshop held within the Technical Co-operation Project on Environmental Restoration in Central and Eastern Europe in Budapest, Hungary, 4-8 October 1993: Planning for environmental restoration of radioactiviely contaminated sites in cent. Vienna, Austria: International Atomic Energy Agency; 1993. DOI: 10.1007/978-3-662-02783-7_10.

[32] Hungarian Atomic Energy Authority. National Report Sixth Report prepared within the framework of the Joint Convention on the Safety of Spent Fuel Management and on the Safety of Radioactive Waste Management. Budapest: 2017. Available from: https://www.oah.hu/web/v3/haeaportal.nsf/ 987F704701527382C1258240004C7081/\$FILE/JC\%206th\%20National\%20Report\%20Hungary.pdf.

[33] Hungarian Central Statistical Office. Meteorological data (1985-). Summ Tables - Time Ser Annu Data Environ. Available from: https://www.ksh.hu/docs/eng/xstadat/xstadat_annual/i_met002cc.html [accessed April 7, 2021].

[34] Hungarian Central Statistical Office. Meteorological Data. Summ Tables - Time Ser Annu Data - Environ 15228 Meteorol Data Pécs*. Available from: https://www.ksh.hu/stadat_files/kor/en/kor0077.html [accessed March 30, 2021].

[35] OrangeSmile.com. Maps of Hungary. Orange Smile. Available from: https://orangesmile.com/travelguide/hungary/country-maps.htm [accessed April 3, 2021].

[36] MSZ 1484-3:2006. Testing of waters. Part 3: Determination of dissolved, suspended and total metals in water by AAS and ICP-OES. Hungarian Stand Board. 2006. Available from: http://www.mszt.hu/web/guest/home [accessed November 1, 2020]. 
[37] Tessier A, Campbell PGC, Bisson M. Sequential extraction procedure for the speciation of particulate trace metals. Anal Chem. 1979;51:844-51. DOI: 10.1021/ac50043a017.

[38] Sungur A, Soylak M, Ozcan H. Investigation of heavy metal mobility and availability by the BCR sequential extraction procedure: Relationship between soil properties and heavy metals availability. Chem Speciat Bioavailab. 2014;26:219-30. DOI: 10.3184/095422914X14147781158674.

[39] Baran A, Tarnawski M. Assessment of heavy metals mobility and toxicity in contaminated sediments by sequential extraction and a battery of bioassays. Ecotoxicology. 2015;24:1279-93. DOI: 10.1007/s10646-015-1499-4.

[40] In: Hasegawa H, Rahman IMM, Rahman MA, editors. Environmental Remediation Technologies for Metal-Contaminated Soils. Tokyo: Springer; 2016: 254 pp. ISBN: 9784431557593. DOI: 10.1007/978-4-431-55759-3.

[41] Sheppard SC, Evenden WG. Bioavailability indices for uranium: Effect of concentration in eleven soils. Arch Environ Contam Toxicol. 1992;23:117-24. DOI: 10.1007/BF00226004.

[42] Vandenhove H, Van Hees M, Wouters K, Wannijn J. Can we predict uranium bioavailability based on soil parameters? Part 1: Effect of soil parameters on soil solution uranium concentration. Environ Pollut. 2007;145:587-95. DOI: 10.1016/j.envpol.2006.04.011.

[43] Neiva AMR, Carvalho PCS, Antunes IMHR, Silva MMVG, Santos ACT, Cabral Pinto MMS, et al. Contaminated water, stream sediments and soils close to the abandoned Pinhal do Souto uranium mine, central Portugal. J Geochemical Explor. 2014;136:102-17. DOI: 10.1016/j.gexplo.2013.10.014.

[44] Pueyo M, Mateu J, Rigol A, Vidal M, Lo JF. Use of the modified BCR three-step sequential extraction procedure for the study of trace element dynamics in contaminated soils. Environ Pollut. 2008;152:330-41. DOI: $10.1016 /$ j.envpol.2007.06.020.

[45] Alshahri F. Uranium and trace metals contamination in topsoil from different zones around industrial city, Al Jubail, Saudi Arabia. Arch Environ Contam Toxicol. 2019;77:308-19. DOI: 10.1007/s00244-019-00642-9.

[46] Skipperud L, Salbu B. Sequential extraction as a tool for mobility studies of radionuclides and metals in soils and sediments. Radiochim Acta. 2015;103:187-97. DOI: 10.1515/ract-2014-2342.

[47] Russell P, Tharmanathan T. Lead and zinc. Wat on Earth. University of Waterloo. Lead Zinc. 2003:November 24. Available from: https://uwaterloo.ca/wat-on-earth/news/lead-and-zinc [accessed April $14,2021]$.

[48] Statstutor. Pearson's Correlation 2015. Available from: https://www.statstutor.ac.uk/ resources/uploaded/pearsons.pdf.

[49] Althouse AD, Soman P. Understanding the true significance of a P value. J Nucl Cardiol. 2017;24:191-4. DOI: $10.1007 / \mathrm{s} 12350-016-0605-1$.

[50] Gavrilescu M, Pavel LV, Cretescu I. Characterization and remediation of soils contaminated with uranium. J Hazard Mater. 2009;163:475-510. DOI: 10.1016/j.jhazmat.2008.07.103.

[51] Zimmerman AJ, Weindorf DC. Heavy metal and trace metal analysis in soil by sequential extraction: A review of procedures. Int J Anal Chem. 2010;2010:1-7. DOI: 10.1155/2010/387803.

[52] Okoro HK, Ige JO, Iyiola OA, Ngila JC. Fractionation profile, mobility patterns and correlations of heavy metals in estuary sediments from olonkoro river, in tede catchment of western region, Nigeria. Environ Nanotechnology, Monit Manage. 2017;8. DOI: 10.1016/j.enmm.2017.04.003.

[53] Pradhanang S. Distribution and fractionation of heavy metals in sediments of Karra River, Hetauda, Nepal. J Inst Sci Technol. 2015;19:123-8. DOI: 10.3126/jist.v19i2.13865.

[54] Pérez-Moreno SM, Gázquez MJ, Pérez-López R, Bolivar JP. Validation of the BCR sequential extraction procedure for natural radionuclides. Chemosphere. 2018;198:397-408. DOI: 10.1016/j.chemosphere.2018.01.108.

[55] Soltani N, Keshavarzi B, Moore F, Sorooshian A, Ahmadi MR, Sciences A, et al. Distribution of potentially toxic elements (PTEs) in tailings, soils, and plants around Gol-E-Gohar iron mine, a case study in Iran. Env Sci Pollut Res Int. 2017;24:18798-816. DOI: 10.1007/s11356-017-9342-5.

[56] Barman M, Datta SP, Rattan RK, Meena MC. Chemical fractions and bioavailability of nickel in alluvial soils. Plant, Soil Environ. 2015;61:17-22. DOI: 10.17221/613/2014-PSE.

[57] Davidson CM, Urquhart GJ, Ajmone-Marsan F, Biasioli M, da Costa Duarte A, Díaz-Barrientos E, et al. Fractionation of potentially toxic elements in urban soils from five European cities by means of a harmonised sequential extraction procedure. Anal Chim Acta. 2006;565:63-72. DOI: 10.1016/j.aca.2006.02.014.

[58] Korychenskyi KO, Laptev GV, Voitsekhovych OV, Lavrova TV, Dyvak TI. Speciation and mobility of uranium in tailings materials at the U-production legacy site in Ukraine. Nucl Phys Atomic Energy. 2018;19(3):270-9. DOI: 10.15407/jnpae2018.03.270. 
[59] Garnier-Laplace J, Colle C, Morello M. Radionuclide fact sheet: Natural uranium and the environment. 2001. Available from: https://www.irsn.fr/EN/Research/publications-documentation/radionuclidessheets/environment/Documents/Uranium_UK.pdf.

[60] Závodská L, Kosorínová E, Scerbakova L, Lesny J. Environmental chemistry of uranium. HUISSN 1418-7108 HEJ Manuscr No ENV-081221-A. 2008;17:1-18. Available from: http://heja.szif.hu/ENV/ENV081221-A/env081221a.pdf.

[61] Wang L, Yu R, Hu G, Tu X. Speciation and assessment of heavy metals in surface sediments of Jinjiang River tidal reach, southeast of China. Environ Monit Assess. 2010;165:491-9. DOI: 10.1007/s10661-009-0961-2.

[62] Kotoky P, Bora BJ, Baruah NK, Baruah J, Baruah P, Borah GC. Chemical fractionation of heavy metals in soils around oil installations. Assam. Chem Speciat Bioavailab. 2003;15:115-26. DOI: 10.3184/095422903782775181.

[63] Zhang W, Wang X, Liu B. An ex-situ immobilization experiment with $\mathrm{Zn}, \mathrm{Pb}$, and $\mathrm{Cu}$ in dredged marine sediments from Bohai Bay, China. J Mar Sci Eng. 2019;7. DOI: 10.3390/jmse7110394.

[64] Ye H, Zang S, Xiao H, Zhang L. Speciation and ecological risk of heavy metals and metalloid in the sediments of Zhalong Wetland in China. Int J Environ Sci Technol. 2015;12:115-24. DOI: 10.1007/s13762-013-0399-5.

[65] Fedotov PS, Dzhenloda RK, Dampilova B V., Doroshkevich SG, Karandashev VK. Unexpected behavior of $\mathrm{Zn}, \mathrm{Cd}, \mathrm{Cu}$, and $\mathrm{Pb}$ in soils contaminated by ore processing after 70 years of burial. Environ Chem Lett. 2018;16:637-45. DOI: 10.1007/s10311-018-0710-2.

[66] Barać N, Škrivanj S, Bukumirić Z, Živojinović D, Manojlović D, Barać M, et al. Distribution and mobility of heavy elements in floodplain agricultural soils along the Ibar River (Southern Serbia and Northern Kosovo). Chemometric investigation of pollutant sources and ecological risk assessment. Environ Sci Pollut Res. 2016;23:9000-11. DOI: 10.1007/s11356-016-6142-2.

[67] Van Herreweghe S, Swennen R, Vandecasteele C, Cappuyns V. Solid phase speciation of arsenic by sequential extraction in standard reference materials and industrially contaminated soil samples. Environ Pollut. 2003;122:323-42. DOI: 10.1016/S0269-7491(02)00332-9.

[68] Bielicka-Giełdoń A, Ryłko E, Zamojć K. Distribution, bioavailability and fractionation of metallic elements in Allotment garden soils using the BCR sequential extraction procedure. Polish J Environ Stud. 2013;22:1013-21. Available from: http://www.pjoes.com/Distribution-Bioavailability-and-Fractionation-rnof-Metallic-Elements-in-Allotment,89057,0,2.html.

[69] Sahito OM, Afridi HI, Kazi TG, Baig JA. Evaluation of heavy metal bioavailability in soil amended with poultry manure using single and BCR sequential extractions. Int J Environ Anal Chem. 2015;95:1066-79. DOI: 10.1080/03067319.2015.1078800.

[70] Sungur A, Soylak M, Yilmaz S, Özcan H. Determination of heavy metals in sediments of the Ergene River by BCR sequential extraction method. Environ Earth Sci. 2014;72:3293-305. DOI: 10.1007/s12665-014-3233-6.

[71] Ma H, Hua L, Ji J. Speciation and phytoavailability of heavy metals in sediments in Nanjing section of Changjiang River. Environ Earth Sci. 2011;64:185-92. DOI: 10.1007/s12665-010-0837-3. 